\title{
Por uma visada genealógica da fotografia contemporânea ${ }^{1}$
}

Fernando do Nascimento Gonçalves

\section{Resumo}

0 texto discute a fotografia na arte contemporânea

a partir de uma abordagem genealógica, propondo considerar o seu passado não como resposta para pensar seu presente, mas como um problema.

Para tanto, o texto busca relacionar algumas das características atuais da fotografia na arte com os processos que a configuraram no século XIX. Sugerese que certas regularidades existentes entre esses períodos históricos podem ser vistas como condição para se compreender algumas das características da fotografia contemporânea, como a "releitura" dos modos de ver e de viver em nossa história recente.

\section{Palavras-Chave}

Fotografia. Genealogia. Arte contemporânea.

\section{Fernando do Nascimento Gonçalves}

Doutor em Comunicação e Cultura - UFRJ, Rio de Janeiro. Pós-Doutor em Sociologia do Cotidiano pela Universidade Paris V-Sorbonne. Professor Associado do PPGCOM-UERJ. Universidade do Estado do Rio de Janeiro (Rio de Janeiro, Rio de Janeiro, Brasil). E-mail: goncalvesfernandon@gmail.com

\section{Introdução}

Uma das principais características da imagem na chamada fotografia contemporânea ${ }^{2}$ é 0 lugar que assume enquanto figura ou objeto de pensamento e não apenas como informação visual ou repositário da memória. Para Michel Poivert (2010), a fotografia contemporânea não reproduziria o que já foi feito na primeira fotografia e na fotografia moderna, mas inventaria com elas uma outra relação. Seu caráter metanarrativo e alegórico complexifica o estatuto da imagem pela acoplagem que faz entre seus aspectos técnico, simbólico e estético, além da discussão sobre sistemas de representação nas histórias da arte e da fotografia e dos modos de presença e legitimação da imagem nos circuitos da arte, na mídia e na internet.

Contudo, tais gestos não são inaugurais, autônomos ou exclusivos da arte ou de nosso presente. Surgem a partir de tensões no interior de distintos campos e momentos históricos, em que 0 estatuto da imagem fotográfica foi e é permanentemente negociado. Do ponto de vista 
dessa negociação, seria possível dizer que 0

presente da fotografia - particularmente na arte, mas não exclusivamente - mira atentamente os processos de construção que forjam sua própria atualidade. Se observarmos as práticas que historicamente organizaram a experiência do fotográfico em seus diferentes circuitos de produção, de circulação e legitimação, veremos que algumas das questões lançadas hoje pela arte sobre os modos de regulação das relações entre dizível e visível já existiam desde o século XIX, 0 que coloca em questão a própria singularidade da chamada fotografia contemporânea ${ }^{3}$.

Não por acaso, Agamben (2009) afirma que a própria noção de "contemporâneo" não seria uma resposta para os dilemas do presente, mas uma pergunta. Para o filósofo italiano, é preciso tomar posição em relação ao nosso presente, em vez de aderir totalmente a ele. Por isso, vai afirmar que, para ser contemporâneo, é preciso ser inatual, no sentido de se ter uma certa desconexão com 0 presente, um recuo, para melhor apreender suas inflexões e dilemas. Nitidamente inspirada nas inquietações nietzscheanas e foucaultianas, a questão encontra eco nas problemáticas colocadas por autores como Benjamin (1993) em seu conceito de História, Didi-Huberman (2015a), em sua história como forma de "conhecimento por montagem" e Ricoeur (1994), em sua concepção de relato histórico como construção narrativa.

Contrariamente a essas perspectivas, um pensamento sobre a fotografia correlato a uma "vontade de verdade" pode ser observado em certas práticas do jornalismo, o qual, por vezes, ainda regula os modos de dizibilidade e visibilidade do real e suas condições de acontecimento. Contudo, como apontou Poivert (2010), foi a própria "utopia documental" que entrou em crise nos anos 1980, na medida em que foi exatamente a crença em uma verdade da imagem que se abalou, inclusive a partir das práticas dos artistas e das teorias da fotografia surgidas nos anos 1970 e 1980. Apesar de já ter sido bastante discutida na comunicação e nas teorias da arte, a crise dessa utopia continua a levantar importantes questões acerca da experiência da imagem fotográfica, especialmente em função de certas formas de sua manifestação na atualidade, que nos fazem refletir sobre seus usos e funções.

0 texto resulta de pesquisa apoiada pelo CNPq e pela Faperj.

Embora o termo "fotografia contemporânea" abarque a experiência do fotográfico em campos diversos e não apenas na arte, será usado aqui para tratar da fotografia no contexto da arte contemporânea.

Seguimos aqui a perspectiva desenvolvida por Didi-Huberman da "iconologia dos intervalos" para dar a ver as regularidades dispersas em intervalos temporais não imediatamente visíveis e que precisam ser recuperados e cerzidos para ganhar visibilidade e legibilidade, de modo a produzir o que ele chamou, a partir de Walter Benjamin e de Aby Warburg, de "conhecimento por montagem" (DIDI-HUBERMAN, 2015).

No sentido de uma afetação da percepção e da apreensão do real, sem reduzir-se apenas a um discurso ou a uma representação/traço do real e sem igualmente abrir mão de sua condição de registro e de sua função de organização do visível. 
Na arte, por exemplo, há pelos menos 40 anos, o documento visual é considerado como um artefato com forte potencial estético ${ }^{4}$ (POIVERT, 2010), portador de uma função alegórica ou de uma "política de imaginação" capaz de restituir a legibilidade de práticas e discursos sociais através da remontagem de outras imagens e dos tempos que as constituem (DIDI-HUBERMAN, 2015a). $\mathrm{Na}$ fotografia vernacular, os usos combinados das imagens analógica e digital, no caso da lomografia, o compartilhamento de imagens no instagram, facebook e snapchat indicam que a imagem vem assumindo, muitas vezes, um caráter relacional e conversacional (GUNTHER, 2015) que parece, em certa medida, desafiar-nos a complexificar os usos clássicos da documentação e da produção de memória. No fotojornalismo, é possível observar as disputas e negociações em torno das condições narrativas e testemunhais, no âmbito de dispositivos de legitimação da imagem, por meio das controvérsias envolvendo fotógrafos como Michael Wolf. Ele ganhou menção honrosa no World Press Photo, em 2011, com suas imagens apropriadas do Google Street View, um ano depois de outro fotógrafo ter sua foto desclassificada por ter sido "trabalhada" a partir de uma imagem "bruta".

Dessas formas de manifestação da fotografia, vai nos interessar aqui a fotografia na arte por ela levantar e realizar esse gênero de questionamento de uma forma mais direta e contundente. 0 interesse em deter-nos na arte para aprofundar os questionamentos sobre a imagem em nosso presente deve-se ao entendimento de que, principalmente, a partir das práticas artísticas e das revisões das teorias da arte e de sua história, têm surgido reflexões renovadas sobre 0 estatuto da imagem, tanto do ponto de vista teórico quanto do das análises empíricas. Sem deter a exclusividade do pensamento sobre a imagem, a arte nos interessa por reconhecer a fotografia como objeto inscrito em diferentes regimes de enunciação que regulam seus modos de produção e de circulação, suas discursividades, seus usos e funções. Tais regimes, como argumentou Rancière (2009), implicam modos de mediação de nossa percepção e de apreensão do sensível na medida em que constroem dele recortes segundo determinados critérios e objetivos.

Apoiado na genealogia como método em Foucault, o texto buscará discutir a construção da historicidade da fotografia como recurso para aprofundar o deslocamento que a arte faz do pensamento sobre a imagem fotográfica para o que considero propriamente sua dimensão comunicativa, isto é, a de uma prática social e histórica que regula as relações entre dizível e visível no campo social.

\section{A genealogia como método é complementar} à perspectiva arqueológica desenvolvida por Foucault para examinar os processos de subjetivação a partir dos discursos e das práticas sociais (LEMOS e JUNIOR, 2009). Com ela, a análise foucaultiana ganhou um novo impulso em seu esforço de romper com as tentativas 
de se estabelecerem relações causais entre os acontecimentos. Nessa abordagem, os fatos são entendidos como construções, pelas relações feitas entre dados e experiências que lhes atribuem valor e sentido "históricos". Não se trata, portanto, de um retorno ao passado para entender a origem dos fatos, mas de examinálo a partir de certas evidências que não são consideradas pela tradição "historicista" ou que são vistas isoladamente. Nesse sentido, uma abordagem genealógica considera que esse passado é também presente, assim como nosso presente é ou foi seu futuro.

Como contribuição para pensar a construção dos estatutos da fotografia ao longo de sua história, a abordagem genealógica poderá nos ajudar a 1) pôr em relação documentos, discursos, dados empíricos, situações de contexto e cruzá-los com elementos de nosso presente, de modo a perceber regularidades talvez ainda pouco visíveis entre eles; 2) tornar legíveis as conexões e regularidades que nos ajudam a entender por que, na arte contemporânea, as imagens são consideradas dispositivos inventariantes e reflexivos; 3) mostrar as disputas que evidenciam como a experiência do trânsito por distintas esferas, intenções e códigos forjam suas condições de produção, recepção e legitimação em nosso presente. Mas tal abordagem permitirá, principalmente, perceber que tais condições de possibilidade e seu entendimento não brotam espontaneamente no presente da arte nem são inaugurados por ela como gesto crítico. É parte dessa história que o texto pretende contar.
Nosso ponto de partida será a primeira Exposição Universal de Paris, em 1855, momento em que a fotografia debutou como invento puramente técnico e científico. Em seguida, procuraremos demonstrar como, no próprio século XIX, essa pureza foi refutada, antecipando algumas atitudes observadas na fotografia contemporânea. Com isso, procuraremos demonstrar que a construção do estatuto da fotografia na arte contemporânea, como dispositivo "inventariante" e "reflexivo" (DA COSTA, 2014), não se deu em função do privilégio dos aspectos poéticos/expressivos sobre os técnicos/objetivos, mas como desdobramento das disputas em que a fotografia foi majoritariamente produzida e legitimada no século XIX: na ciência, na arte e na indústria.

A partir dessas disputas, veremos como a fotografia foi sempre marcada por seu duplo aspecto de objeto e de mediação técnica e cultural, e como tal ambiguidade esteve presente desde o começo da experiência do fotográfico. É o que nos permite discutir a fotografia não apenas como tecnologia de registro ou modo expressivo, mas como prática social e histórica. É como tal que a fotografia inscreve-se no que Michel Callon (2008) chamou de "redes sociotécnicas" - redes de relações que conectam pessoas e coisas em âmbitos diversos (científico, histórico, cultural, artístico, econômico e político) - nas quais, uma vez conectados, tais elementos se afetam reciprocamente, criando e transformando permanentemente realidades materiais e imateriais na vida social. 
Essa proposição implica considerar que a fotografia apresenta necessariamente muitas histórias e também muitas maneiras de contálas. Dentro da questão que nos interessa, é importante lembrar que a história da fotografia como tecnologia de registro e máquina de visão começa com a configuração dos modos de ver que a antecederam (CRARY, 2012) até sua legitimação como "meio", com direito a usos e funções bem definidas. Contudo, no próprio século XIX já era possível observar uma série de usos que problematizavam essa objetividade e essa função de registro e que evidenciavam a condição da fotografia como organizadora da percepção e de produtora de "realidade". A observação do surgimento de determinadas controvérsias envolvendo certos usos da fotografia nesse período permite contaminar aos poucos a suposta pureza de suas intenções e de suas narrativas. Isso fica claro nas disputas presentes na primeira Exposição Universal de Paris, realizada em 1855, e também em seu relatório, publicado em 1856.

\section{A fotografia na Exposição Universal de 1855}

\section{A Exposição Universal de 1855 em Paris foi} uma oportunidade de compartilhar e difundir amplamente as mais recentes descobertas científicas, produtos, técnicas e também obras de arte, além de aproximá-las de industriais, comerciantes, colecionadores, aficionados e do público em geral. Aconteceu em dois grandes locais, segundo duas grandes divisões: "produtos da indústria”, apresentados no Palácio da Indústria, e "obras de arte", apresentados no Palácio das Belas Artes.

Ser aceito para participar da Exposição já era uma grande honra. Mas, uma vez aceitos, os objetos passavam por um novo filtro: a localização no evento, que lhes conferiria uma maior ou menor visibilidade, segundo determinados critérios e modos de classificação. Além disso, todo invento, produto ou obra de arte exposto era julgado, e os vencedores recebiam prêmios de um júri. Após a Exposição, um relatório era elaborado e tornado público, o qual servia como indicador de caminhos a serem seguidos pelos objetos da arte e pelos experimentos científicos, influenciando o desenho das políticas públicas e privadas de desenvolvimento técnico-científico em nível internacional e favorecendo (ou não) a produção e a venda de determinados produtos, obras e tecnologias.

Segundo Rouillé (1985), a fotografia fazia parte da divisão "Produtos da Indústria". Mais especificamente, compunha a "quarta sessão" da "classe 26" ("desenho e plástica aplicados à indústria", impressão "em caracteres", "em sistema flexível" e "fotografia"). Tal classe, por sua vez, fazia parte do Grupo VII ("móveis e decorações", "moda", "desenho industrial", "impressão" e "música"), conforme indicado no relatório da Exposição (1856). A despeito dos protestos de entusiastas e de representantes de Sociedade Francesa de Fotografia, criada em 
1851, a fotografia foi designada como um objeto "útil" e não como "arte", e a ela coube um espaço modesto na Exposição, por seu estágio ter sido considerado, pelo júri, ainda embrionário, e sua aplicabilidade aos interesses da indústria, tímida.

Esse julgamento aparece no relatório de 1856, que aponta duas tendências para a fotografia como invento e produto: a primeira é 0 desencorajamento do uso do daguerreótipo, e 0 segundo é 0 estímulo da técnica de impressão do negativo em vidro por colódio, que favorecia a produção e reprodução das provas em menos tempo, com maior qualidade e com custo mais baixo. Para decepção de seus defensores, o júri dera destaque também, com as devidas premiações e referências em seu relatório, a projetos e iniciativas com técnicas de impressão não fotográficas por contato, como a litografia e a heliografia. A justificativa era de que estas haviam demonstrado mais rapidez e eficácia na conservação das tiragens e por terem um procedimento de reprodução mais mecânico e menos sujeito a alterações que os procedimentos químicos usados até então.

Ao mesmo tempo, o relatório reconhece a importância do uso aplicado da fotografia na indústria, como o registro de imagens de flores e seu uso na fabricação de tecidos ou na produção de tiragens para instrumentalizar a fabricação de modelos de peças e móveis. Também por seu uso científico (nas pesquisas da botânica, da zoologia, da medicina e nas expedições etnográficas e arqueológicas), a fotografia havia recebido prêmios por suas contribuições nos processos de observação, análise e extração de leis explicativas para os fenômenos estudados. Finalmente, no campo da arte, a fotografia demonstrara ter sido muito útil como modelo de apoio à criação de pintores, escultores, gravadores e arquitetos, pela fidelidade de seus registros.

De toda forma, percebe-se que, à época, apesar de já se esboçar para a fotografia um "campo próprio", por meio da formação de grupos de praticantes amadores, profissionais e de associações especializadas, é quase sempre a tecnicidade aplicada que emerge como valor e sentido "legítimos" para a fotografia Sintomaticamente, 0 retrato, uma das práticas fotográficas mais difundidas naquele mesmo período, foi também desqualificado no evento. Criticando abertamente a proliferação dos fabricantes de portraits, o júri iria considerá-los como detratores da fotografia por terem objetivo puramente mercantil e por a tratarem mais como "curiosidade do que (algo) de utilidade real" (ROUILLÉ, 1985, p. 94). e fazia da visão uma experiência neutra e objetiva, conformando os modos de percepção do indivíduo moderno. Também Peter Galassi (1981), ao confrontar a história da fotografia com a da pintura, demonstrou como, em muitos momentos, a fotografia deu continuidade ao projeto de figuração naturalista e mimética da pintura acadêmica, igualmente inscrita no paradigma da câmera obscura. 
Entre disputas e elogios, a Exposição Universal

foi, por isso mesmo, também, lugar de atualização da crescente querela com a arte, campo no qual a fotografia reivindicava um lugar, em pé de igualdade com a pintura, a escultura e a gravura. Mas, no interior do próprio campo nascente da fotografia, os interesses defendidos por alguns fotógrafos e membros da Sociedade Francesa de Fotografia (que buscavam afirmar a prática fotográfica como gênero expressivo) rivalizavam com interesses comerciais, na figura de Adolphe Disdéri, que, curiosamente, era o fotógrafo "oficial" do evento.

Animada por um desejo manifesto de difundir descobertas e novos produtos que contribuíssem para a transformação da sociedade, sem deixar, porém, de atender às lógicas de mercado, a Exposição Universal de 1855 teve por efeito conferir um público sem precedentes à fotografia, constituindo um marco importante para ela. No entanto, evidenciou também que a fotografia iria passar por um momento de transição como invento, do ponto de vista das técnicas de produção e de suas funções, que apareciam tanto nos usos preconizados pela indústria, pela ciência e pela arte quanto nas disputas internas ao próprio campo.

Naquele momento, valores como precisão e rapidez construíam o estatuto da fotografia como tecnologia de registro aplicada à produção e não como objeto voltado à expressão ou ao consumo, embora isso já acontecesse e fosse uma tendência atestada pela popularização das cartes de visite e dos álbuns de família. A construção e projeção dessa concepção era viabilizada não só pela desqualificação de práticas que fugiam ao modelo utilitarista preconizado pela ciência, pela arte e pela indústria quanto pela notória orientação de que a fotografia enquanto invento deveria vencer os obstáculos técnicos, econômicos e culturais que a impediam de estar em conformidade com os "tempos modernos". Isso, porém, não impediu que a invenção de novas técnicas de impressão, de processos químicos e tipos de papel permitisse 0 surgimento e 0 desenvolvimento de práticas que buscaram complexificar a função da fotografia de "duplicar o real", como se observa não só no âmbito do movimento pictorialista (FABRIS, 2008), mas também no seio da própria indústria e da ciência, como veremos mais adiante.

Por meio das distintas experiências do fotográfico no século XIX - que construíam a fotografia como forma neutra de registro e forma expressiva com pretensões de "arte" -, o que vai lentamente se desenhando são modos de fazer ciência, arte e objetos para o consumo, além de formas de construir a memória, visões de mundo e estilos de vida. Dessas experiências, entre defesas da "objetividade" e da "subjetividade", a fotografia vai sendo testada e reinventada até alcançar, nas primeiras décadas do século XX, sua "autonomia" e "linguagem" enquanto meio, excluindo e legitimando determinados usos e funções, talhados pelas dinâmicas de que fazia parte. 
É essa "autonomia" da fotografia enquanto meio que vem sendo discutida e problematizada no âmbito da arte contemporânea. Por um lado, é na arte contemporânea, por exemplo, que a fotografia parece adquirir 0 estatuto de um artefato sociotécnico ${ }^{6}$ cuja natureza é tanto técnica quanto expressiva, e cujo interesse desloca-se da representação mimética para constituir-se como elemento de reflexão sobre a construção dos modos de ver e de se relacionar através das imagens. Por outro, esse deslocamento não é exclusivo da arte. No youtube e em fóruns de discussão na internet, por exemplo, é possível encontrar cada vez mais vídeos em que fotógrafos profissionais e pessoas comuns ensinam ou trocam experiências sobre como produzir imagens com a técnica do daguerreótipo, do cianótipo ou do colódio úmido, pelos efeitos particulares que possibilitam nos processos de produção da imagem. Também nos sites de redes sociais, como Facebook e Instagram, é possível observar como a produção, os usos e apropriações das imagens mostram, dentre outras coisas, como estas já não valem apenas como conteúdo ou registro, mas como forma de aludir a fatos, de produzir ficções de si, de construir narrativas não lineares e de gerar fluxos conversacionais (GUNTHER, 2015).

Assim como essas experiências fora do campo da arte, o que a Exposição Universal de 1855 nos ajuda a iluminar são os processos que configuram desde 0 início a experiência do fotográfico como dispositivo de mediação técnico-cultural. É tal aspecto que será assumido pela arte contemporânea como um valor para a fotografia, a partir do qual esta começará a ser considerada como "arte" entre os anos 70 e 80 do século XX (POIVERT, 2010), quando deixa de estar vinculada apenas a funções como registrar e narrar o real e vai buscar discutir tais funções como construções históricas de nossos modos de ver e de viver em sociedade.

Por sua natureza de artefato - investido não só de "tecnicidade", mas também de memórias, desejos e intenções -, a fotografia contém os traços da mobilização desses elementos em seus usos e funções. Portanto, mais do que respostas, os usos da fotografia na arte ou fora dela precisam ser investigados por fazerem parte dos conjuntos de relações que os constroem e legitimam. É o que tentaremos mostrar a seguir.

\section{Três questões para uma "técnica"}

Sem a pretensão de produzir análises totalizantes para a experiência da fotografia no século XIX, o que nos propomos agora é observar e discutir alguns traços e evidências que envolvem parte da história da fotografia e indicam como, 
em determinados momentos, produzem-se condições particulares para sua legitimação e problematização. Em função dos limites estreitos do texto, analisaremos brevemente a experiência do fotográfico nos campos da ciência, da indústria e das artes do século XIX, a partir de três casos que funcionarão como pontos de entrada nas redes sociotécnicas ${ }^{7}$ que envolvem e configuram usos e funções da fotografia nesses campos e que concorrem tanto para sua legitimação quanto para sua problematização.

No campo científico, uma das situações que evidencia um uso "expressivo" e mesmo performático - e não eminentemente "técnico" - da fotografia como forma de obter registros "objetivos" foi a iconografia fotográfica do hospital Salpetrière. Ela foi construída entre 1876 a 1880 pelo médico Jean-Martin Charcot, que com ela elaborou a noção de histeria no campo da psiquiatria. Os usos da fotografia e de outras formas de registro (como a pintura e o desenho) nesse contexto foram importantes aliados para a observação, a documentação, a catalogação, a classificação, o diagnóstico e 0 tratamento do que à época se convencionou chamar de histeria. Apesar de ser um fato localizado, a discussão da iconografia de Salpetrière remete, de forma mais ampla, à construção do saber científico no século XIX, no qual se insere a própria fotografia e temas não menos importantes, como os estudos da fisiologia do movimento, em Marey, e a cronofotografia em Muybridge.

0 pacto de Charcot com a fotografia para formular e comprovar cientificamente suas teses sobre a histeria teria sido perfeito se a fotografia, em seu estágio de desenvolvimento técnico naquele período, permitisse o registro instantâneo das crises das internas e não exigisse a reencenação das crises para fins de estudos e pesquisas, como demonstrou Didi-Huberman (2012). Aqui fica claro como a empiria e a objetividade científicas (como requisitos para validar um conhecimento) são fabricadas através da fotografia de modo a permitir à psiquiatria não apenas validar a tese da histeria, mas também legitimá-la enquanto ciência.

No segundo campo, da indústria e do comércio, por sua vez, é possível observar como o desenvolvimento científico participa da configuração das técnicas e dos processos de produção fotográfica e, ao mesmo tempo, é por eles configurado. 0 ponto de entrada aqui serão as cartes de visite, criadas por Adolphe Eugène Disdéri. Híbrido de objeto "técnico" e "artístico", as cartes de visite participavam, a mesmo tempo, da construção do sujeito moderno por meio do retrato e da popularização da própria fotografia na segunda metade do século XIX. Seu formato 
diminuto e de baixo custo falava tanto da crise do valor da unicidade da imagem e do tempo lento de sua produção (daguerreótipo) quanto do surgimento e da legitimação de técnicas que melhor atendiam aos novos imperativos de velocidade, quantidade e nitidez da indústria. Falava também das relações dessa crise com os avanços da química e com as mudanças na pintura, na gravura e na própria produção de imagens fotográficas. A convergência entre ciência, arte e indústria, contudo, prepara aqui tanto 0 caminho para a construção e legitimação do caráter comercial e documental da fotografia quanto 0 de sua contestação.

Como vimos na Exposição Universal, retratos e paisagens pictóricos, por exemplo, poderiam ser reconhecidos como "arte", desde que, claro, figurassem como imitações verossímeis do real, como demonstrou Rancière (2009) em sua "partilha do sensível". 0 mesmo não ocorreria com os retratos e as paisagens fotográficas, exatamente por terem sido objeto de uma outra partilha, em que se definiu que seu lugar seria 0 de objeto "útil", e não "belo". Tal lugar evidencia, por isso, outras disputas. A fotografia não poderia ser uma "forma expressiva", caso contrário rivalizaria com a pintura. Portanto, não poderia ser mais que uma forma mecânica de registro a serviço da arte com "A" maiúsculo (como esfera de saber/poder instituído) e, logo, inferior, nada tendo de "artística". Outra disputa é com a ciência. A fotografia construída artificialmente, seja nos estúdios fotográficos ou nas intervenções dos pictorialistas, ameaçava o princípio da mimese, que não interessava não só à arte, mas também à ciência, que não prescindia do registro objetivo e de sua "seriedade" como invento para legitimar-se como prática social e de poder.

Finalmente, o terceiro campo de observação, a arte, evidencia como as invenções da ciência e da indústria são correlatas às discussões sobre técnica, genialidade, originalidade e modos de ver nesse mesmo período. Por um lado, o surgimento de técnicas de registro mais eficazes, rápidas e baratas (como a litografia e a heliografia) favoreceu a difusão e 0 acesso às obras de arte (pondo em questão, inclusive, a competência da própria fotografia, como ficou claro na Exposição Universal de 1855, pelo estágio técnico da invenção à época). Por outro lado, diminui a distância entre as vontades de verdade do saber científico e da arte.

Nossa entrada nesse imbróglio será através das fotomontagens do pintor e fotógrafo pictorialista 0skar Gustav Rejlander e suas intervenções e montagens de negativos, com as quais conferia à imagem fotográfica um aspecto pictórico, ficcional e de mis-en-scène. Rejlander ficou conhecido por suas teatralizações de situações cotidianas, em 
que a fotografia não era um fim, mas um meio narrativo com o qual buscava alçar a fotografia ao estatuto de "belas artes". Porém, mais do que tratar do trabalho de Rejlander como simples pretensão da fotografia em ser "arte" e de negar sua "natureza" técnica de registro e seu caráter documental (o que reiteraria a clássica oposição entre arte e fotografia na figura da dicotomia utilitarismo-documentação x ficção-expressão), 0 interesse aqui será evidenciar como essa oposição remete, na verdade, à construção de uma concepção de fotografia reduzida ou apenas a seus aspectos documental e de registro ou a seu caráter subjetivo e de ficçã $0^{9}$.

A rigor, qualquer processo fotográfico realizado por meios físico-químicos implica algum grau de manipulação. Não é novidade que a produção de uma imagem analógica, depende tanto do tempo de exposição quanto dos aspectos ópticos, dos tipos de técnica de ampliação e de impressão e do tipo de papel. Não falamos aqui da construção da pose, de tipos de enquadramento ou cortes na imagem, mas da "edição" nos próprios processos de produção físico-química da imagem.

Curiosamente, são essas possibilidades consideradas obsoletas do ponto de vista de um certo uso e de uma função preconizados para a imagem - em nome da facilidade e da rapidez da ampliação e do tratamento da imagem - que hoje voltam a encantar profissionais, amadores e artistas e se multiplicam por meio de tutoriais no youtube. 0 que ficou conhecido como os primeiros processos de "manipulação fotográfica" veio não dos usos profissionais de produtos químicos ou de lentes e tipos de papel e tempo de exposição, mas do que à época foram considerados "acidentes" ou "erros" de revelação de negativos realizados por amadores (FERNANDES, 2012). É o caso das imagens de negativos distintos aparecendo inesperadamente na mesma fotografia - sobretudo devido à má lavagem das placas de colódio. Como o ideal de "qualidade" era dado pela definição da imagem, a duração de sua fixação e da harmonização dos tons de cinza, esse e qualquer outro "desvio" que comprometesse seu uso como documento, dentro dos critérios existentes, eram motivos para se descartar uma imagem ou para não a aceitar como fotografia "útil" ou "bela".

Somente aos poucos tais acidentes começaram a ser explorados intencionalmente, como na composição de vários negativos para formar uma nova imagem, a exemplo dos panoramas ou

Esses aspectos supostamente opostos deixam de sê-lo no âmbito da arte contemporânea em função de sua inscrição no que Rancière chamou de "regime estético das artes". Neste, existiria não uma suspensão da relação entre inteligível e visível, mas a invenção de uma outra maneira de entender a enunciação do real, que remete à superação de uma lógica que historicamente subordina e hierarquiza texto e palavra, representação e narrativa, correspondente ao "regime mimético" (mímese como condição de enunciação e da representação), encarnado em certas concepções da fotografia na ciência, na indústria e na própria arte no século XIX, como vimos. No "regime estético", a ruptura não se produziria pela passagem de um regime enunciativo de representação para o de uma não representação ou de uma apresentação ou na ruptura da relação do inteligível com 0 sensível, mas pelo surgimento do que ele chamou exatamente de um "novo estatuto da figura" (RANCIERE, 2010, p. 177). Nesse outro estatuto, a figura conjugaria - sem homogeneizar - dois regimes de expressão considerados distintos e quase sempre considerados opostos: 0 de uma presença de algo e o da representação dessa presença. 
dos tableaux-vivants. Feitas através de recortes, superexposição, sobreimpressão, da repetição do mesmo negativo ou mesmo da combinação de vários desses processos, essas produções ficaram conhecidas à época como "impressões combinadas".

Ainda que as suas origens sejam imprecisas, surgem, já em meados do século XIX, várias publicações dedicadas a esse "divertimento". Segundo Fernandes (2012), a fotomontagem surge num primeiro momento dentro de um contexto popular e, não raro, humorístico e de entretenimento, tendo sido bastante explorada em cartazes, charges e postais. Apenas mais tarde, fotógrafos "profissionais", como os pictorialistas, passaram a se interessar pela fotomontagem, por retoques e intervenção nos negativos.

Rejlander foi um deles e ficou conhecido por suas "dramatizações do real" e justaposições temporais na imagem, como na emblemática Two Ways of Life (1857), tableau vivant em que combinou trinta e dois negativos para recompor L'École d'Athènes, de Raphael, de 1511, uma alegoria da virtude e do pecado.

Tal gesto, associativo e reflexivo, implicava uma outra atitude diante da imagem, que a toma não apenas como registro objetivo ou neutro, mas como campo de jogo com o real, onde a figuração está a serviço de uma narrativa imaginativa e alegórica, uma das características da fotografia contemporânea (POIVERT, 2010). É verdade que, para Rejlander, tal imaginação visava a construir imagens o mais próximo possível a uma estética pictórica na qual se reproduziam os critérios e valores vitorianos de sua época. Contudo, essas experimentações, que já naquela época ampliavam as possibilidades dos usos e das funções da imagem fotográfica, apenas recentemente foram consideradas pioneiras do ponto de vista da criação com a fotografia. Também foram consideradas pioneiras como recurso estético que guarda muitas semelhanças com as experimentações de fotógrafos que trabalham, por exemplo, com a crítica da cultura por meio de gestos de interferência, apropriação, reencenação e performatização, como Joaquim Schmidt, Marc Baruth, Cindy Sherman e Jeff Wall.

Porém, mesmo fazendo referência a uma pintura reconhecida como a de Rafael, e se apresentando em um grande formato, próprio das pinturas alegóricas do período (e atualmente também de muitas fotografias contemporâneas), apenas dois anos após sua realização, Two Ways of Life foi reconhecido e adquirido - a preço baixo - pela coleção real britânica. 0 motivo: a imagem era muito controversa, pois considerava-se inapropriado uma fotografia mostrar nudez, um tema para a "arte", mas não para a fotografia. Sua rejeição inicial, tanto como "arte" quanto como "ciência" (tampouco pouco era uma imagem "séria" ou "verdadeira", apenas uma montagem, uma trapaça; no máximo, um divertimento), concedeu-lhe inicialmente 0 estatuto de indesejada, de freak. 
Mais uma vez, observa-se como os domínios da arte, da ciência e da indústria se atravessam e se imbricam, evidenciando o quanto os usos "aplicados" ou "expressivos" da imagem são eles próprios construídos, além, naturalmente, das próprias concepções do que é "aplicado" e "expressivo". Se, na fotografia contemporânea, a imagem não vai simplesmente registrar e mostrar o mundo, mas observar os modos de produção das imagens e as lógicas que lhe conferem valor e sentido para uma construção de mundo, é porque, historicamente, tanto nos campos da ciência, da arte e da indústria, essa construção já era empreendida segundo tais lógicas, embora isso nem sempre fosse assumido.

Como apontou Rancière (2010), desde o final do século XIX, a partir de mudanças não apenas na arte, mas também na ciência, na indústria, na cultura, na economia e na política, fica mais evidente a coexistência de um regime enunciativo baseado na mimese com um regime em que a imagem não se confunde com aquilo que representa e é considerada como um modo de regular as relações entre visível e dizível. É de tal coexistência que surge a possibilidade de legibilidade de práticas e discursos sociais e da própria arte a partir da fotografia. É de tal coexistência que é forjado seu "estatuto inventariante" na atualidade, particularmente no contexto da arte, em que o documento fotográfico passou a ser considerado não apenas como um dispositivo de representação, mas também como dispositivo que permite discutir a representação como questão de enunciação, tanto na arte quanto fora dela.

A partir de uma visada "inatual" ou "anacrônica", a fotografia contemporânea evidencia, assim, a natureza híbrida da imagem como documento e invenção que regula nossas relações com o sensível. Contudo, reitero que a percepção desta natureza híbrida não é, em si, nova nem inaugurada pela arte contemporânea. Ela está presente nas controvérsias que envolvem ciência, indústria, arte, fotografia e suas histórias. Se na fotografia contemporânea testemunho e memória, informação e história, materialidade do documento e invenção do real não se opõem nem se reduzem à mimese (antes se reconfiguram como um campo de tensão e de produção de sentido), é porque na fotografia contemporânea as mediações técnicas e sociais que a imagem sempre realizou passaram a constituir propriamente uma questão central para 0 entendimento das experiências da imagem na atualidade. Deste modo, mais que uma categoria "nova", "específica" e "autônoma", a fotografia contemporânea seria uma forma social e histórica que 1) discutiria tanto 0 abalo na crença da verdade absoluta do índice, do documento e do testemunhal, nas noções de belo, de gênero e de narrativa quanto os rearranjos desses elementos na atualidade; $\mathrm{e}$ 2) produziria outras formas sentir, de perceber, de comunicar e de nos relacionar com a imagem e através da imagem. 
Portanto, não é por acaso que muitas das fotografias produzidas e apresentadas nos circuitos da arte contemporânea parecem encontrar ressonâncias com a chamada primeira fotografia e também com a fotografia moderna. Observando trabalhos de artistas como Nam Goldin, Thomas Struth, Sophie Ristelhueber, Rineke Dijskstra, Candida Hofer, Andreas Gursky e, no Brasil, Rosângela Rennó, Alice Miceli, Pedro David, Marcelo Tinoco ou Claudia Jaguaribe, é possível verificar não apenas a recorrência de temas (retrato e autorretrato, paisagem, naturezamorta) da história da arte, mas principalmente um fazer imagem que relê nossas formas de representar e de produzir narrativas sobre 0 mundo. Se esses e outros artistas não estão interessados em registrar pessoas, lugares e coisas, mas em inventariar e discutir nossas relações com a história, com a identidade, com 0 corpo e com os espaços naturais e construídos, é porque nossas experiências com pessoas, coisas e lugares sempre foram objeto de uma construção e de uma partilha, exatamente como os objetos na Exposição Universal de 1855.

\section{Considerações finais}

Partindo da concepção da fotografia como uma prática em disputa inscrita em uma rede sociotécnica, o texto buscou apontar, ainda que brevemente, indícios de como, desde o século XIX, construiu-se e, ao mesmo tempo, refutou-se um estatuto único para fotografia. Tanto essa construção quanto essa contestação atravessaram boa parte da experiência do fotográfico até nossos dias, e o redimensionamento de sua condição de tecnologia de registro parece ser condição necessária para pensarmos a experiência da fotografia hoje na arte e fora dela, embora tais condições existissem no século XIX e já permitissem práticas contemporâneas às de nosso presente.

As iconografias de Salpetrière, as cartes de visites e as fotomontagens pictorialistas foram invocadas aqui como figuras de práticas e discursos sociais costurados pelo fio da imagem fotográfica, presentes também na Exposição Universal de 1855, que aqui constitui uma alegoria dessa tessitura. No presente do século XIX, três "mapas" formam um só. 0 entrecruzamento desses fragmentos de práticas e questões na abordagem da fotografia como "história" e prática em disputa evidencia o quanto a experiência do fotográfico é enredada por aspectos e elementos diversos para pensá-la, ou apenas do ponto de vista de sua natureza "técnica" - com a qual se fez prevalecer para a fotografia uma função objetiva e neutra de registro e de documentação - ou apenas "expressiva" - com a qual se faz prevalecer seu aspecto subjetivo, de invenção ou de ficção.

Como tentei demonstrar, esses caracteres "objetivos" e "subjetivos" da fotografia foram construídos a partir do imbricamento de distintos discursos, práticas e interesses. Foram também mobilizados de diferentes formas e com diferentes objetivos em diferentes contextos, embora apenas 
o caráter objetivo tenha sido legitimado em função de um alinhamento com uma lógica de neutralidade/objetividade herdada do paradigma moderno de visão da câmera escura. Parece ficar claro, assim, como a vocação eminentemente documental e de produção de memória da fotografia foi sendo construída e legitimada enquanto função social precípua desde o século XIX até individuarse como meio, linguagem e saber visual, ao longo do século XX, sob as formas de experiências e designações diversas como "fotografia direta", "documental", "fotojornalística", até começar a entrar em crise no final do século XX e passar a ser considerada, principalmente na arte, como recurso estético e dispositivo de observação e análise de nossos modos de vida em sociedade.

Após uma série de disputas ocorridas ao longo de sua história, nos campos da arte, da ciência, da indústria, da história e da comunicação, outras reconfigurações da técnica, da memória e da experiência social parecem revolver novamente a fotografia. Tais reconfigurações, que deslocam cada vez mais a análise da imagem fotográfica como mensagem visual para a dos processos que constroem seus sentidos e modos de presença, permitem-nos vincular a fotografia aos atos e regimes enunciativos que a produzem, dentro e fora da arte. Se, para ser "contemporâneo", como preconiza Agamben, é preciso entrecruzar passado, presente e futuro, esta é também uma aposta nas possibilidades que a fotografia oferece para realizarmos uma leitura inatual de nosso próprio presente.

\section{Referências bibliográficas}

AGAMBEN, G. 0 que é o contemporâneo? e outros ensaios. Chapecó: Argos, 2009.

BENJAMIN, W. Magia e Técnica, Arte e Política. Vol.1. 6a edição. São Paulo: Brasiliense, 1993.

\section{CALLON, Michel. Entrevista com Michel}

Callon: dos estudos de laboratório aos estudos de coletivos heterogêneos, passando pelos gerenciamentos econômicos. Sociologias [online]. n.19, pp. 302-321, 2008.

DA COSTA, Luiz Cláudio. A gravidade da imagem: arte e memória na contemporaneidade. Rio de Janeiro: Quartet, 2014.

DIDI-HUBERMAN, G. Diante do tempo. Belo Horizonte: UFMG, 2015.

A invenção da histeria. Rio de Janeiro: Contraponto, 2015.

CRARY, J. Técnicas do observador. Rio de Janeiro: Contraponto, 2012.

EXPOSITION UNIVERSELLE DE 1855. Rapports du jury mixte international publiés sous la direction de S.A.I. le Prince Napoléon, président de la Commission impériale, Paris, Imprimerie impériale, Paris, 1856, vol. 1, p. I-LXXVI.

FABRIS, A. (Org). Fotografia: usos e funções no século XIX. São Paulo: Edusp, 2008.

FERNANDES, M. A Fotomontagem no Século XIX: da mecânica à narratologia. In Revista Rhêtorikê. n. 4., pp. 37-76, 2012.

GALASSI, P. Before Photography. The Museum of Modern Art. New York, 1981.

GUNTHER, A. L'Image partagée. Paris, Éditions Textuel, 2015.

LATOUR, B. Reagregando o social. Salvador/ Bauru: UDUFBA/EDUSC, 2012. 
LEMOS, F e JÚNIOR, H. A genealogia em Foucault:

uma trajetória. In: Psicologia \& Sociedade; 21 (3), 2009.

POIVERT, M. La Photographie Contemporaine. Paris:

Flammarion, 2010.

RANCIERE, J. A partilha do sensível. 2 ed. Rio de Janeiro: Ed. 34. 2009.

. 0 espectador emancipado. Lisboa:

Orfeu Negro, 2010.

RICOEUR, P. Tempo e Narrativa (tomo 1). Campinas:

Papirus, 1994.

ROUILLÉ, A. La photographie française à

l'Exposition universelle de 1855. №. 131,

L'Expression Plastique au XIXe Siècle Regards

d'Aujourd'hui. Apr-Jun, 1985. 


\section{For a genealogy approach} of contemporary photography

\section{Por una mirada genealógica de la fotografia contemporanea}

\section{Abstract}

The text discusses contemporary photography from a genealogical approach, proposing to consider the past of photography not as an answer to its present, but also as a problem. For this, the text seeks to relate some of current characteristics related to photography in art with the processes that shaped the photographic experience in the 19th century. It is suggested that there are existing regularities which might be seen as a condition for understanding some of the characteristics of photography in contemporary art, as the "rereading" of modes of vision and of living in our recent history.

\section{Keywords}

Photography. Genealogy. Contemporary Art.

\section{Resumen}

El texto discute la fotografía contemporánea a partir de un enfoque genealógico, proponiendo considerar el pasado de la fotografía no como respuesta para pensar su presente, sino también como un problema. Para esto, el texto busca relacionar algunas de las características actuales relacionados con la fotografia en el arte con los procesos que la configuraron en el siglo XIX. Se sugiere que las regularidades existentes entre estos momentos históricos puedan ser vistas como condición para comprender algunas de las características de la fotografía en el arte contemporaneo, como a "relectura" de los modos de visión y de vida en sociedad en nuestra historia reciente.

\section{Palabras-clave}

Fotografía. Genealogía. Arte Contemporáneo. 


\section{Expediente}

A revista E-Compós é a publicação científica em formato eletrônico da Associação Nacional dos Programas de Pós-Graduação em Comunicação (Compós). Lançada em 2004, tem como principal finalidade difundir a produção acadêmica de pesquisadores da área de Comunicação, inseridos em instituições do Brasil e do exterior.

\section{E-COMPÓS I www.e-compos.org.br I E-ISSN 1808-2599}

Revista da Associação Nacional dos Programas de Pós-Graduação em Comunicação. Brasília, v.21, n.2, maio/ago. 2018. A identificação das edições, a partir de 2008, passa a ser volume anual com três números. Indexada por Latindex I www.latindex.unam.mx

\section{CONSELHO EDITORIAL}

Ada Cristina Machado Silveira, Universidade Federal de Santa Maria, Brasil Alda Cristina Silva da Costa, Universidade Federal do Pará, Brasil Alfredo Luiz Paes de Oliveira Suppia, Universidade Estadual de Campinas, Brasil Ana Regina Barros Rego Leal, Universidade Federal do Piauí, Brasil Ana Carolina Rocha Pessôa Temer, Universidade Federal de Goiás, Brasil André Luiz Martins Lemos, Universidade Federal da Bahia, Brasil Angela Cristina Salgueiro Marques, Universidade Federal de Minas Gerais, Brasil Ângela Freire Prysthon, Universidade Federal de Pernambuco, Brasil Anna Cristina Pertierra, Western Sidney University - Australia Antonio Carlos Hohlfeldt, Pontifícia Universidade Católica do Rio Grande do Sul, Brasil Arthur Ituassu, Pontifícia Universidade Católica do Rio de Janeiro, Brasil Bruno Campanella, Universidade Federal Fluminense, Brasil Bushra Rahman, University of the Punjab, Paquistão Cláudio Novaes Pinto Coelho, Faculdade Cásper Líbero, Brasil Cárlida Emerim, Universidade Federal de Santa Catarina, Brasil Carlos Del Valle Rojas, Universidad de La Frontera, Chile Carlos Eduardo Franciscato, Universidade Federal de Sergipe, Brasil Danilo Rothberg, Universidade Estadual Paulista, Brasil Denise Tavares da Silva, Universidade Federal Fluminense, Brasil Diógenes Lycarião, Universidade Federal do Ceará, Brasil Doris Martines Vizcarrondo, Universidad de Porto Rico, Porto Rico Eduardo Vicente, Universidade de São Paulo, Brasil Eliza Bachega Casadei, Escola Superior de Propaganda e Marketing - SP, Brasil Elvira Gomes dos Reis, Universidade do Cabo Verde, Cabo Verde Eneus Trindade, Universidade de São Paulo, Brasil Erick Felinto de Oliveira, Universidade do Estado do Rio de Janeiro, Brasil Erick Torrico, Universidad Andina Simón Bolívar, Bolívia Erly Vieira Júnior, Universidade Federal do Espírito Santo, Brasil Fabio La Rocca, Université Paul Valéry Montpellier III, França Fernando Firmino da Silva, Universidade Federal da Paraíba, Brasil Francisco de Assis, FIAM-FAAM Centro Universitário, Brasil Francisco Elinaldo Teixeira, Universidade Estadual de Campinas, Brasil Francisco Gilson R. Pôrto Jr., Universidade Federal do Tocantins, Brasil Francisco Sierra Caballero, Ciespal, Equador

Frederico de Mello Brandão Tavares, Universidade Federal de Ouro Preto, Brasil Gabriela Reinaldo, Universidade Federal do Ceará, Brasi Gérman Rey, Pontifícia Universidad Javeriana, Colômbia Gilson Vieira Monteiro, Universidade Federal do Amazonas, Brasil Gustavo Daudt Fischer, Universidade do Vale do Rio dos Sinos, Brasil Gustavo Hernández Díaz, Universidad Central de Venezuela, Venezuela Heidi Figueroa Sarriera, Universidad de Puerto Rico, Porto Rico Ignacio Aguaded, Universidad Huelva, Espanha

Inesita Soares de Araújo, FIOCRUZ, Brasil Itania Maria Mota Gomes, Universidade Federal da Bahia, Brasil Jiani Adriana Bonin, Universidade do Vale do Rio dos Sinos, Brasil João Carlos Correia, Universidade de Beira Interior, Portugal Jonathan Cohen, da University of Haifa, Israel José Afonso da Silva Junior, Universidade Federal de Pernambuco, Brasil José Luiz Aidar Prado, Pontifícia Universidade Católica de São Paulo, Brasil Josette Maria Monzani, Universidade Federal de São Carlos, Brasil Juçara Gorski Brittes, Universidade Federal de Ouro Preto, Brasil Julián Durazo Herrmann, Université du Québec à Montréal Juliana Freire Gutmann, Universidade Federal da Bahia, Brasil
Karla Covarrubias, Universidad de Colima, México Laura Loguercio Cánepa, Universidade Anhembi Morumbi, Brasil Leonel Azevedo de Aguiar, Pontifícia Universidade Católica do Rio de Janeiro, Brasil Letícia Cantarela Matheus, Universidade do Estado do Rio de Janeiro, Brasil Ling Chen, Hong Kong Baptist University Luciana Coutinho Souza, Universidade de Sorocaba, Brasil Maria Ataide Malcher, Universidade Federal do Pará, Brasil Maria Elena Hernández Ramírez, Universidad de Guadalajara, México Maria Elisabete Antonioli, Escola Superior de Propaganda e Marketing - SP, Brasil Maria das Graças Pinto Coelho, Universidade Federal do Rio Grande do Norte, Brasil Maria Teresa Quiroz, Universidad de Lima, Peru Marialva Carlos Barbosa, Universidade Federal do Rio de Janeiro, Brasil Marina Poggi, Universidad Nacional de Quilmes, Argentina Marcel Vieira Barreto Silva, Universidade Federal da Paraíba, Brasil Marcia Tondato, Escola Superior de Propaganda e Marketing, Brasil Marli Santos, Universidade Metodista de São Paulo, Brasil Márcio Souza Gonçalves, Universidade do Estado do Rio de Janeiro, Brasil Mateus Yuri Passos, Universidade Metodista de São Paulo, Brasil Mauricio Mario Monteiro, Universidade Anhembi Morumbi, Brasil Mayka Castellano, Universidade Federal Fluminense, Brasil Mirna Varela, Universidad de Buenos Aires, Argentina Mozahir Salomão Bruck, Pontifícia Universidade Católica de Minas Gerais, Brasil Neyla Pardo, Universidad Nacional de Colombia, Colombia Nísia Martins Rosario, Universidade Federal do Rio Grande do Sul, Brasil Olga Guedes Bailey, Nottingham Trent University, Inglaterra Paolo Demuru, Universidade Paulista, Brasil Paolo Peverini, L.O.U.I.S.S de Roma, Itália

Paško Bilić, Institute for Development and International Relations, Croácia Paula Melani Rocha, Universidade Estadual de Ponta Grossa, Brasil Potiguara Mendes Silveira Jr, Universidade Federal de Juiz de Fora, Brasil Priscila Ferreira Perazzo, Universidade Municipal de São Caetano do Sul, Brasil Rafael Cardoso Sampaio, Universidade Federal do Paraná, Brasil Rafael Tassi Teixeira, Universidade Tuiuti do Paraná, Brasil Regiane Lucas Garcês, Universidade Federal de Minas Gerais, Brasil Regiane Regina Ribeiro, Universidade Federal do Paraná, Brasil Renata Pitombo Cidreira, Universidade Federal do Recôncavo da Bahia, Brasil Renato Essenfelder, Escola Superior de Propaganda e Marketing, Brasil Roberto Elísio dos Santos, Universidade Municipal de São Caetano do Sul, Brasil Robson Borges Dias, Universidade Católica de Brasília (UCB), Brasil Rodolfo Rorato Londero, Universidade Estadual de Londrina, Brasil Rosario Sánchez Vilela, Universidad Católica del Uruguay, Uruguai Roseli Figaro, Universidade de São Paulo, Brasil

Saima Saeed, Jamia Millia Islamia, India Sara Brandelero, Leyden University, Holanda

Simone Maria Andrade Pereira de Sá, Universidade Federal Fluminense, Brasil Sônia Caldas Pessoa, Universidade Federal de Minas Gerais, Brasil Sun Sun Lim, Singapore University of Technology and Design, Singapura Tatiana Oliveira Siciliano, Pontifícia Universidade Católica do Rio de Janeiro, Brasil Thaïs de Mendonça Jorge, Universidade de Brasília, Brasil Valquiria Michela John, Universidade Federal do Paraná, Brasil Vicki Mayer, Tulane University, Estados Unidos Yamile Haber Guerra, Universidad de Oriente, Cuba 


\section{CONSELHO CIENTÍFICO}

Cristiane Freitas Gutfreind, Pontifícia Universidade Católica do Rio Grande do Sul, Brasil I Eduardo Antônio de Jesus, Universidade Federal de Minhas Gerais, Brasil | Eduardo Morettin, Universidade de São Paulo, Brasil I Irene de Araújo Machado, Universidade de São Paulo, Brasil | Miriam de Souza Rossini, Universidade Federal do Rio Grande do Sul, Brasil

\section{COMISSÃO EDITORIAL}

Igor Pinto Sacramento, Universidade Federal do Rio de Janeiro, Brasil । Kelly Cristina de Souza Prudencio, Universidade Federal do Paraná, Brasil । Osmar Gonçalves dos Reis Filho, Universidade Federal do Ceará, Brasil | Rafael Grohmann, Faculdade Cásper Líbero, Brasil | Thaiane Moreira de Oliveira, Universidade Federal Fluminense, Brasil (editores associados)

\section{CONSULTORES AD HOC}

Alessandro Constantino Gamo, Universidade Federal de São Carlos (UFSCAR) | Amanda Mauricio Pereira Leite, Universidade Federal do Tocantins (UFT) | Amílcar Almeida Bezerra, Universidade Federal de Pernambuco (UFPE) I Ana Carolina Damboriarena Escosteguy, Universidade Federal de Santa Maria (UFSM) I Ana Luiza Coiro Moraes, Faculdade Cásper Líbero | Antonio Pacca Fatorelli, Universidade Federal do Rio de Janeiro (UFRJ) | Ariane Diniz Holzbach, Universidade Federal Fluminense (UFF) I Benjamin Picado, Universidade Federal Fluminense (UFF) I César Augusto Baio dos Santos, Universidade Federal do Ceará (UFC) I César Geraldo Guimarães, Universidade Federal de MInas Gerais (UFMG) I César Ricardo Siqueira Bolaño, Universidade de Brasília (UNB) I Ciro Marcondes Filho, Universidade de São Paulo (USP) I Felipe Simão Pontes, Universidade Estadual de Ponta Grossa I Felipe Trotta, Universidade Federal Fluminense (UFF) I Gislene da Silva, Universidade Federal de Santa Catarina (UFSC) I Kati Caetano, Universidade Tuiuti do Paraná I Laan Mendes de Barros, Universidade Estadual Paulista Júlio de Mesquita Filho I Lucia Leão, Pontifícia Universidade Católica de São Paulo (PUC-SP) I Jairo Getulio Ferreira, Universidade do Vale do Rio dos Sinos (UNISINOS) | Juliana Doretto, FIAM-FAAM | Juliano Maurício de Carvalho, Universidade Estadual Paulistaa Júlio de Mesquita Filho | Lilian Cristina Monteiro França, Universidade Federal de Sergipe I Liziane Soares Guazina, Universidade de Brasília (UNB) I Luís Mauro Sá Martino, Faculdade Cásper Líbero | Luiz Peres Neto, Escola Superior de Propaganda e Marketing (ESPM) I Herom Vargas, Universidade Metodista de São Paulo I Inês Silvia Vitorino Sampaio, Universidade Federal do Ceará (UFC) I Maria Helena Weber, Universidade Federal do Rio Grande do Sul (UFRGS) I Mariana Baltar, Universidade Federal Fluminense (UFF) I Maurício de Bragança, Universidade Federal Fluminense (UFF) I Mauro de Souza Ventura- Universidade Estadual Paulista Júlio de Mesquita Filho I Muniz Sodre de Araujo Cabral, Universidade Federal do Rio de Janeiro (UFRJ) I Nuno Manna, Universidade Federal da Bahia (UFBA) I Rosana de Lima Soares, Universidade de São Paulo (USP) I Sandra Maria Lúcia Pereira Gonçalves, Universidade Federal do Rio Grande do Sul (UFRGS) I Sérgio Luiz Gadini, Universidade Estadual de Ponta Grossa I Talitha Gomes Ferraz, Escola Superior de Propaganda e Marketing (ESPM) I Victa de Carvalho Pereira da Silva, Universidade Federal do Rio de Janeiro (UFRJ)

\section{EQUIPE TÉCNICA}

ASSISTENTES EDITORIAL Melina Santos | REVISÃO DE TEXTOS Fátima Áli | EDITORAÇ̃̃o ELETRÔNICA Roka Estúdio

COMPÓS I www.compos.org.br

Associação Nacional dos Programas de Pós-Graduação em Comunicação

Presidente

Marco Roxo

Programa de Pós-Graduação em Comunicação - UFF marcos-roxo@uol.com.br

Vice-Presidente

Isaltina Gomes

Programa de Pós-Graduação em Comunicação - UFPE

isaltina@gmail.com

Secretária-Geral

Gisela Castro

Programa de Pós-Graduação em Comunicação

e Práticas de Consumo - ESPM

castro.gisela@gmail.com

CONTATO I revistaecompos@gmail.com 